\title{
P01-047 - PH with right-sided heart failure in FMF
}

\author{
AV Sargsyan ${ }^{1 *}$, MZ Narimanyan ${ }^{2}$ \\ From 7th Congress of International Society of Systemic Auto-Inflammatory Diseases (ISSAID) \\ Lausanne, Switerland. 22-26 May 2013
}

\section{Introduction}

FMF is associated with pulmonary hypertension(PH) due to amyloidosis. However, clinically overt $\mathrm{PH}$ with right-sided heart failure remains a rare event limited to few patients with pulmonary amyloidosis secondary to FMF. We report two cases of FMF patients, with and without amyloidosis, who experienced $\mathrm{PH}$ with rightsided heart failure. To our knowledge, this is the first case report on cor pulmonale in FMF patient without amyloidosis.

\section{Case report}

\section{First}

A.R.,72 year old non-smoker male presented with 6-month history of cough, dyspnea and intensive weight loss $(8 \mathrm{~kg})$. He had typical FMF abdominal and chest attacks since the age of 28 . He took colchicine irregularly,during attacks only. He gave a positive family history. His daughter (40, has had FMF attacks since the age of 35) and cousin brothers were also affected. No history of occupational exposure. Series of X-ray and thoracic CT scan demonstrated unilateral ground-glass opacities in a basal segment of right lung and cardiomegaly. Echocardiography showed hypertrophy of left ventricle, dilated right ventricle, tricuspid regurgitation, and $\mathrm{PH}$, findings compatible with cor pulmonale. Upper GI endoscopy with gastric biopsy revealed atrophic gastritis. Laboratory investigations revealed: CRP $79.2 \mathrm{mg} / \mathrm{L}$, SAA $210 \mathrm{~g} / \mathrm{L}$, creatinin $162.1-189 \mu \mathrm{mol} / \mathrm{l}$ and proteinuria $0.19 \mathrm{~g} /$ daily. Two months later patient died of heart failure. Postmortem examination showed emphysema, lung fibrosis and sclerosis, myocardial hypertrophy and kidney arteriolosclerosis. Daughter's genetic test revealed one mutation in exon 2 in the heterozygous state $\mathrm{E} 148 \mathrm{Q} / \mathrm{N}$.

\section{Second}

S.H.,47 year old male, a smoker, presented with cough, progressive dyspnea and pedal edema. He had typical FMF abdominal and chest attacks since early childhood. He gave a positive family history. His sister and brother were also affected. He took colchicine irregularly, during attacks only. Genetic test showed compound heterozygosity (M694V M680IG/C). ElectroKG showed atrial fibrillation and low QRS voltage in the limb leads. Doppler ECG demonstrated biventricular wall thickening, dilated right ventricle, diastolic dysfunction, and pulmonary hypertension. Laboratory investigations revealed: creatinin $172.4 \mu \mathrm{mol} / \mathrm{l}$, proteinuria $1.4 \mathrm{~g} /$ daily. CT demonstrated diffuse interstitial lung infiltrates and bullas (marked air cysts). Eight months later, patient died of heart failure. Postmortem examination showed extensive deposits of amyloid in the kidneys, pulmonary vasculature, alveolar septa, pleura and myocardium.

\section{Discussion}

FMF patients with chest attacks may develop PH. If present, $\mathrm{PH}$ is a sign of advanced disease, and the survival rate after diagnosis is low. A diagnosis of $\mathrm{PH}$ should be considered in patients with and without amyloidosis and unexplained dyspnea or fluid overload. Although pulmonary involvement may occur in FMF, $\mathrm{PH}$ with right sided heart failure is considered an infrequent diagnosis and is rarely the cause of death.

\section{Disclosure of interest}

A. Sargsyan Consultant for: clinical and lab tests, M. Narimanyan Consultant for: clinical and lab tests.

\footnotetext{
Authors' details

${ }^{1}$ Internal Medicine, Yerevan, Armenia. ${ }^{2}$ Family Medicine, Yerevan State

Medical University, Yerevan, Armenia.

Published: 8 November 2013
}

${ }^{1}$ Internal Medicine, Yerevan, Armenia

Full list of author information is available at the end of the article 


\section{References}

1. Dingli D, Utz PJ, Gertz MA: PH in patients with amyloidosis. Chest 2001, 120:1735-1739.

2. Johnson WJ, Lie JT: PH and FMF: a previously unrecognized association. Mayo Clin Proc 1991, 66:919-25.

3. Lidar M, Langevitz P, Livneh A, Pras M: Thoracic and lung involvement in FMF. Clin Chest Med 2002, 23(2):505-11.

4. Utz JP, Swensen SJ, Gertz M: Pulmonary amyloidosis.The Mayo Clinic experience from 1980 to 1993. Ann Intern Med 1996, 124:407-13.

doi:10.1186/1546-0096-11-S1-S1

Cite this article as: Sargsyan and Narimanyan: P01-047 - PH with rightsided heart failure in FMF. Pediatric Rheumatology 2013 11(Suppl 1):A50.

Submit your next manuscript to BioMed Central and take full advantage of:

- Convenient online submission

- Thorough peer review

- No space constraints or color figure charges

- Immediate publication on acceptance

- Inclusion in PubMed, CAS, Scopus and Google Scholar

- Research which is freely available for redistribution

Submit your manuscript at www.biomedcentral.com/submit 